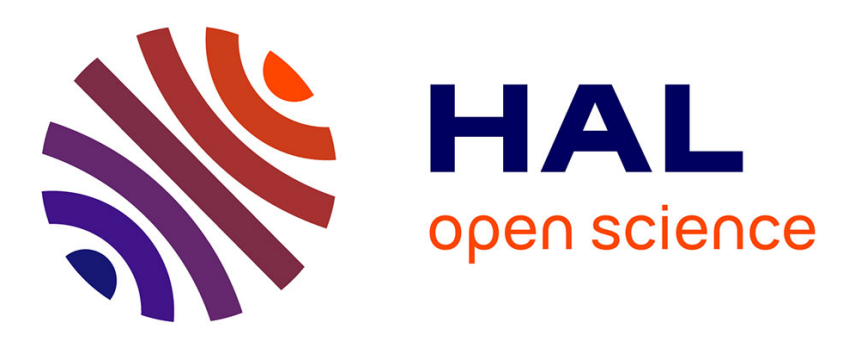

\title{
Inversion of thermodiffusive properties of ionic colloidal dispersions in water-DMSO mixtures probed by forced Rayleigh scattering
}

M. Sarkar, J. Riedl, G. Demouchy, F. Gélébart, G. Mériguet, V. Peyre, E. Dubois, R. Perzynski

\section{To cite this version:}

M. Sarkar, J. Riedl, G. Demouchy, F. Gélébart, G. Mériguet, et al.. Inversion of thermodiffusive properties of ionic colloidal dispersions in water-DMSO mixtures probed by forced Rayleigh scattering. European Physical Journal E: Soft matter and biological physics, 2019, 42 (6), pp.72. 10.1140/epje/i2019-11835-6 . hal-02275964

\section{HAL Id: hal-02275964 https: / hal.sorbonne-universite.fr/hal-02275964}

Submitted on 2 Sep 2019

HAL is a multi-disciplinary open access archive for the deposit and dissemination of scientific research documents, whether they are published or not. The documents may come from teaching and research institutions in France or abroad, or from public or private research centers.
L'archive ouverte pluridisciplinaire HAL, est destinée au dépôt et à la diffusion de documents scientifiques de niveau recherche, publiés ou non, émanant des établissements d'enseignement et de recherche français ou étrangers, des laboratoires publics ou privés. 


\title{
Inversion of thermodiffusive properties of ionic colloidal dispersions in water-DMSO mixtures probed by forced Rayleigh scattering
}

\author{
M. Sarkar ${ }^{1}$, J. Riedl ${ }^{1}$, G. Demouchy ${ }^{1,2}$, F. Gélébart ${ }^{1}$, G. Mériguet $^{1}$, V. Peyre ${ }^{1}$, E. Dubois ${ }^{1}$, and R. Perzynski ${ }^{1}$ \\ 1 Sorbonne Université, CNRS, PHysico-chimie des Electrolytes et Nanosystèmes InterfaciauX, F-75005 Paris - France \\ 2 Département de Physique - Univ. Cergy-Pontoise, 33 bd du port 95011 Cergy-Pontoise - France
}

\begin{abstract}
Thermodiffusion properties at room temperature of colloidal dispersions of hydroxyl-coated nanoparticles (NPs) are probed in water, in dimethyl sulfoxide (DMSO) and in mixtures of water and DMSO at various proportions of water, $x_{\mathrm{W}}$. In these polar solvents, the positive NPs superficial charge imparts the systems with a strong electrostatic interparticle repulsion, slightly decreasing from water to DMSO, which is here probed by Small Angle Neutron Scattering and Dynamic Ligth Scattering. However if submitted to a gradient of temperature, the NPs dispersed in water with $\mathrm{ClO}_{4}^{-}$counterions present a thermophilic behavior, the same NPs dispersed in DMSO with the same counterions present a thermophobic behavior. Mass diffusion coefficient $D_{\mathrm{m}}$ and Ludwig-Soret coefficient $S_{\mathrm{T}}$ are measured as a function of NP volume fraction $\Phi$ at various $x_{\mathrm{W}}$. The $\Phi$-dependence of $S_{\mathrm{T}}$ is analyzed in terms of thermoelectric and thermophoretic contributions as a function of $x_{\mathrm{W}}$. Using two different models for evaluating the Eastman entropy of transfer of the co- and counterions in the mixtures, the single-particle thermophoretic contribution (the NP's Eastman entropy of transfer) is deduced. It is found to evolve from negative in water to positive in DMSO. It is close to zero on a large range of $x_{\mathrm{W}}$ values, meaning that in this $x_{\mathrm{W}}$-range $S_{\mathrm{T}}$ largely depends on the thermoelectric effect of free co- and counterions.
\end{abstract}

\section{Introduction}

When submitted to a gradient of temperature $\nabla T$, ionic nanoparticles (NPs) dispersed in a polar solvent are subjected both to the Ludwig-Soret effect [1], which induces a gradient of volume fraction $\boldsymbol{\nabla} \Phi$ and a Seebeck effect [2,3], which induces an electric field $\boldsymbol{E}$. This can be used for potential thermoelectric applications in terms of heat recovery [4-10]. In stationary conditions, both $\boldsymbol{\nabla} \Phi$ and $\boldsymbol{E}$ are proportional to $\boldsymbol{\nabla} T$ and the NPs migrate either towards the cold region or towards the hot region depending on the sign of their Soret coefficient $S_{T}$, given (at high dilution) by $\nabla \Phi=-\Phi S_{\mathrm{T}} \boldsymbol{\nabla} T$. Their Seebeck coefficient $S_{e}^{\mathrm{St}}$ is given by $\boldsymbol{E}=S_{e}^{\mathrm{St}} \boldsymbol{\nabla} T$ and it is connected to $S_{\mathrm{T}}$, through $\hat{S}_{\mathrm{NP}}$, the Eastman entropy of transfer of the nanoparticles in the solvent ${ }^{1}[2,12-15]$. This single-particle contribution $\hat{S}_{\mathrm{NP}}$ characterizes the affinity of the ionic NPs with the polar solvent in which they are dispersed [12,15-17]. $S_{\mathrm{T}}$ depends on the interparticle interaction (thus on the NP's concentration and that of counterions), but also on the nature of these counterions and on the nature of the solvent [17-19].

1 The entropy of transfer $\hat{S}_{\mathrm{i}}$ of ionic species $i$ is defined as in [11] as $Q_{\mathrm{i}}^{*} / T$ with $Q_{\mathrm{i}}^{*}$ the heat of transport of ionic species $i$.
In the present study, we focus on two polar solvents with a very different structural organization, namely dimethyl sulfoxide (DMSO, $\mathrm{H}_{3} \mathrm{C}-\mathrm{SO}-\mathrm{CH}_{3}$ ) and water. Water is a polar protic solvent strongly structured through a H-bond network [20], while DMSO is a less organized, aprotic and polar organic solvent, with a lower dielectric permittivity $\varepsilon_{\mathrm{DMSO}}=46[21]$ than water at room temperature. Mixtures of water and DMSO are chosen for this study as they are miscible in any proportions in these conditions. Using perchlorate $\left(\mathrm{ClO}_{4}^{-}\right)$counterions, the same acidic magnetic nanoparticles can be dispersed in both solvents, with the same type of electrostatic stabilization giving stable magnetic ferrofluids [18,19]. Here the strong electrostatic interparticle repulsion imparts the two kinds of colloidal dispersions with similar properties. However in the presence of a temperature gradient, the same maghemite NPs present a thermophilic behaviour in water $\left(S_{T}<\right.$ 0) $[16,18,19]$ while they present a thermophobic one $\left(S_{T}>\right.$ $0)$ in DMSO $[6,18,19]$.

In order to follow progressively this change of thermodiffusive behaviour at room temperature, colloidal dispersions of maghemite NPs (9 $\mathrm{nm}$ in diameter) are dispersed in water and in DMSO at comparable $\left[\mathrm{H}^{+}\right]$concentration $\left(\sim 10^{-2} \mathrm{~mol} \mathrm{~L}^{-1}\right)$ with perchlorate counterions. Dispersions in water-DMSO mixtures are then prepared at various mole fractions of water $x_{W}$, various NP vol- 
ume fraction $\Phi$ and same $\left[\mathrm{H}^{+}\right]$. The colloidal structure of the dispersions and the interparticle electrostatic repulsion are determined by Small Angle Neutron Scattering and the electrophoretic charge of the NPs is determined (at low volume fraction) by electrophoretic measurements and Dynamic Light Scattering (DLS). We present here a forced Rayleigh scattering (FRS) study of these dispersions.

The samples probed here with the different techniques (SANS, DLS, FRS) have the same ionic concentration $\left[\mathrm{H}^{+}\right]=10^{-2} \mathrm{~mole} / \mathrm{L}$ for all the $x_{\mathrm{W}}$ solvent compositions studied.

After a presentation of the synthesis and charaterization of the probed dispersions and that of the FRS experiment, we show and discuss the results obtained for the mass diffusion coefficient $D_{m}$ of the NPs and the Soret coefficient $S_{\mathrm{T}}$ as a function of $\Phi$ and $x_{W} . S_{\mathrm{T}}$ is then analyzed with the model presented in [16] in terms of thermophoretic and thermoelectric contributions.

\section{Preparation and characterization of the colloidal dispersions}

\subsection{Solvent characteristics}

Like water, DMSO is a polar molecular solvent. It is a green grade solvent with low toxicity used in pharmacological applications, recyclable and biodegradable [22]. DMSO has amphiphilic properties with a strongly polar sulfoxide group and two hydrophobic methyl moities. Being aprotic and $\mathrm{H}$ bond acceptor, it is miscible with water in any proportion above the DMSO melting point $\left(T>18^{\circ} \mathrm{C}\right)$ in atmospheric conditions. Water-DMSO form an eutectic mixture $2 \mathrm{H}_{2} \mathrm{O}: 1 \mathrm{DMSO}$ at $x_{\mathrm{W}}=66 \%$, liquid down to $T=-73^{\circ} \mathrm{C}[23]$. At room temperature the viscosity of DMSO is roughly twice that of water while their densities are very similar (see E.S.I. Table S1). The mixture viscosity, as well as its density present a non-ideal behavior with a maximum for molar-fractions of water $x_{\mathrm{W}} \sim 66 \%$ corresponding to the eutectic mixture [24-26]. Other physical characteristics such as the thermal conductivity $k[27,28]$, the static relative permittivity $\varepsilon_{\mathrm{r}}[29,30]$ and the optical index $n[24,25]$ of water-DMSO mixtures do not present such a pronounced non-ideal behaviour and are monotonous functions of $x_{\mathrm{W}}$ at room temperature; $\varepsilon_{\mathrm{r}}$ decreases (almost linearly) from 80 in water down to 46 in DMSO [29-32] and $n$ increases from 1.33 in water up to 1.47 in DMSO $[24,25]$.

These macroscopic properties are connected to molecular scale interactions between water and DMSO, in particular through $\mathrm{H}$-bonds and van der Waals forces. $\mathrm{H}$ bond interactions are transient in nature, with ultrafast breaking and making processes and various kinds of $\mathrm{H}-$ bond associations are possible between water and DMSO molecules. A crossover is found in Ref. [33] for the Hbond exchange rate at $x_{\mathrm{W}} \sim 85 \%$, which is associated to the fact that water-DMSO mixtures act as protein stabilizers and activators for $x_{\mathrm{W}}>85 \%$, while for $x_{\mathrm{W}}<85 \%$ they act as denaturators and inhibitors. In [34], hydrogenbond population was numerically quantified on the whole range of $x_{\mathrm{W}}$. Several structural studies, both experimental and numerical, have shown concentration-dependent organizations of water and DMSO molecules [35], structural microheterogeneities [36], the formation of chains of water molecules [37] or of network structures [38].

\subsection{Chemical synthesis of the NP's dispersions}

Ferrite NPs are synthesized following Massart's method $[39,40]$ by poly-condensation of ferric and ferrous salts in strongly alkaline aqueous medium followed by an hydrothermal oxidation at $100^{\circ} \mathrm{C}$ under atmospheric pressure with nitric acid [41] leading to roughly spherical maghemite $\left(\gamma-\mathrm{Fe}_{2} \mathrm{O}_{3}\right)$ nanoparticles, coated with hydroxyl groups. A size-sorting of the NPs as the one described in Ref. [42] is performed. All the present dispersions are based on the same initial batch of NPs.

These NPs can be easily dispersed in water at $\mathrm{pH} \sim 2$, where they are positively charged. They have a point of zero charge $(\mathrm{PZC}) \sim 7-8$ in water, where they flocculate. The method described in $[18,19]$ is used here to tune the NP-solvent interface in water and in DMSO. Starting from a flocculated aqueous dispersion at PZC, all extraions and all the water molecules (that can be removed) are then eliminated by repeated washings. Then the NPs are charged in the chosen medium following a controlled and reproducible process to obtain NP's dispersions with perchlorate counterions (added in known quantity) at $\left[\mathrm{H}^{+}\right]=$ $10^{-2} \mathrm{~mol} \mathrm{~L}^{-1}$, either in water or in DMSO at a NP's volume fraction $\Phi \sim 2.5 \%$. A portion of the obtained dispersions is ultracentrifugated at $2 \times 10^{5} \mathrm{~g}$. Providing that the ultracentrifugation does not perturb the local equilibria around NPs, concentrations of free co-ions $\mathrm{H}^{+}$and counterions $\mathrm{ClO}_{4}^{-}$are determined in each dispersion by conductivity measurements in the supernatant. A solution similar to the supernatant is then used to obtain dilute dispersions at lower $\Phi$ in the same solvent. Dispersions in water-DMSO mixtures are obtained by mixing in the adapted proportion a dispersion in water and a dispersion in DMSO at the same $\Phi$ and the same ionic concentration.

Both in water and in DMSO, stable acidic dispersions with a long term stability (more than 15 years ${ }^{2}$ ) are obtained with positively charged NPs (hydroxyl groups - acidic medium).

\subsection{Characterization of NPs and of their dispersions}

The magnetization of a dilute aqueous dispersion (at $\Phi \sim 1 \%$ ) up to $800 \mathrm{kA} \mathrm{m}^{-1}$ is determined at room temperature with a home-made Vibrating Sample Magnetometer (data not shown). The size distribution of the magnetic nanoparticles can then be deduced following the procedure of Ref. [43]. It is adjusted with a log-normal distribution of diameter, of median diameter $d_{0}=7.5 \mathrm{~nm}$ and

\footnotetext{
${ }^{2}$ as attested in DMSO by the DLS measurements presented in Section S6 of E.S.I..
} 

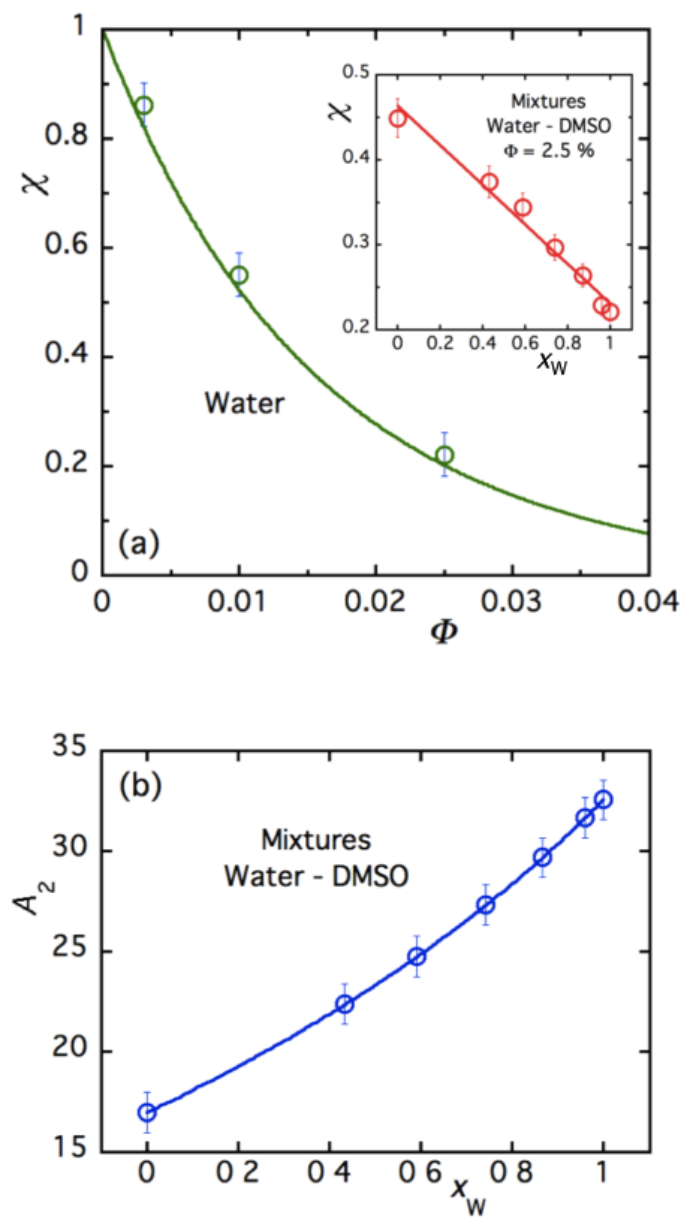

Figure 1. (a) : Osmotic compressibility $\chi$ as a function of the NP's volume fraction $\Phi$ in water; Open symbols: SANS results; Full line: $\chi_{\mathrm{CS}}$ adjustment with Eq. 2 ; Inset: Osmotic compressibility $\chi$ as a function of $x_{\mathrm{W}}$ in mixtures at $\Phi=2.5 \%$; Open symbols: Experimental SANS results; Full line: Linear adjustment; (b) : $A_{2}$ as a function of $x_{\mathrm{W}}$ in mixtures as deduced from SANS determinations and Eq. 3 (open symbols) and as interpolated with the Carnahan-starling model (full line).

polydispersity index 0.35 , leading to a volume-averaged diameter $d_{\mathrm{NP}}=\sqrt[3]{\left\langle d^{3}\right\rangle}=9.0 \mathrm{~nm}$.

Dynamic Light Scattering measurements are performed in very dilute dispersions (at $\Phi \sim 0.2 \%$ ) in water and in DMSO between $T=22^{\circ} \mathrm{C}$ and $40^{\circ} \mathrm{C}$ and in various mixtures at $T=22^{\circ} \mathrm{C}$ with a Vasco DLS particle analyzer from Cordouan Technologies dedicated to dark media. It allows to determine the NP's diffusion coefficient $D^{\mathrm{DLS}}$.

The dynamic electrophoretic charge number $\xi_{0}$ of the NPs and its derivative $\partial \xi_{0} / \partial T$ are deduced (as in Ref. [16, $17]$ ) in water and in DMSO from $D^{\mathrm{DLS}}$ and from measurements of the NP's electrophoretic mobility $\mu_{\mathrm{el}}$ at $\Phi \sim$ $0.01 \%$ with a NanoZS from Malvern (with a dip cell) for $25 \leq T \leq 40^{\circ} \mathrm{C}$, using:

$$
\xi_{0}=\frac{k T \mu_{\mathrm{el}}}{e D^{\mathrm{DLS}}} \quad \text { at } \Phi \rightarrow 0
$$

leading to $\xi_{0}=65 \pm 6$ and $\partial \xi_{0} / \partial T=0.4 \pm 0.2 \mathrm{~K}^{-1}$ in water; and $\xi_{0}=43 \pm 4$ and $\partial \xi_{0} / \partial T=0.5 \pm 0.2 \mathrm{~K}^{-1}$ in DMSO. The values of $\xi_{0}$ and $\partial \xi_{0} / \partial T$ for the various mixtures probed here are obtained by a linear interpolation of $x_{\mathrm{W}}$ between the values in pure water and in pure DMSO. As in $[16,17]$, this effective charge $\xi_{0}$ is of the same sign but much smaller than the structural charge of the NPs, which is due the hydroxyl species $\mathrm{H}^{+}$present at the maghemite surface $(\sim$ 2 charges per $\mathrm{nm}^{2}$, leading to a structural charge number $\sim 450$ ). This difference has to be related here to a large amount of $\mathrm{ClO}_{4}^{-}$species condensed on the surface.

Small Angle Neutron Scattering measurements are performed at PACE - LLB - Saclay - France in the range of scattering vectors $Q\left(2.4 \times 10^{-3} \AA \leq Q \leq 4.3 \times 10^{-1} \AA\right)$ on various dispersions. The form factor of the nanoparticles is deduced in water as a function of the scattering vector $Q$ by extrapolation at $\Phi=0$ of the intensities of three dispersions at $0.3 \%, 1 \%$ and $2.5 \%$. We follow the same procedure as in [19] to deduce the osmotic compressibility $\chi$ of the NP system from the scattered intensity at finite volume fraction. Fig. 1a presents the evolution of $\chi$ in water as a function of the NP volume fraction $\Phi$. As the interparticle repulsion is strong in these colloidal dispersions stabilized electrostatically, $\chi(\Phi)$ is here adjusted (as in $[16-19,44])$ by the Carnahan-Starling expression for effective hard spheres $[45,46]$ of volume fraction $\Phi_{\text {eff }}$ (and effective diameter taking in account the screening length $\kappa^{-1}$ ) as:

$$
\chi(\Phi)=\chi_{\mathrm{CS}}\left(\Phi_{\mathrm{eff}}\right)=\frac{\left(1-\Phi_{\mathrm{eff}}\right)^{4}}{1+4 \Phi_{\mathrm{eff}}+4 \Phi_{\mathrm{eff}}^{2}-4 \Phi_{\mathrm{eff}}^{3}+\Phi_{\mathrm{eff}}^{4}} .
$$

The second virial coefficient $A_{2}$ of the osmotic pressure $\Pi$ in the dispersion then writes:

$$
A_{2}=A_{2}^{\mathrm{HS}} \frac{\Phi_{\mathrm{eff}}}{\Phi}=4 \frac{\Phi_{\mathrm{eff}}}{\Phi} \quad \text { with } \quad \Phi_{\mathrm{eff}}=\Phi\left(1+\frac{2 \kappa^{-1}}{d_{\mathrm{NP}}}\right)^{3}
$$

with $A_{2}^{\mathrm{HS}}=4$, the hard sphere value of $A_{2}$.

We obtain $A_{2}=33 \pm 3$ and $\kappa^{-1}=4.6 \pm 0.4 \mathrm{~nm}$ for the aqueous samples. Inset of Fig. 1a shows the evolution of $\chi$ as a function of $x_{\mathrm{W}}$ obtained for the mixtures waterDMSO at constant $\Phi=2.5 \%$. For the analysis, the same NP's form factor as in water is kept to deduce $\chi$. The formalism of Eqs. 2 and 3 then allows to obtain $\Phi_{\text {eff }}$ and $A_{2}$ as a function of $x_{\mathrm{W}}$ (see Fig. 1b). It leads to $A_{2}=$ $17 \pm 2$ and $\kappa^{-1}=2.8 \pm 0.4 \mathrm{~nm}$ in DMSO. These $\kappa^{-1}$ values in water, DMSO and their mixtures are experimentally consistent with the values $\epsilon_{\mathrm{r}}$ of the relative permittivity in these media [32] and they roughly scale as $\kappa^{-1} \sim 0.47 \sqrt{\epsilon_{\mathrm{r}}}$ (in $\mathrm{nm}$ ).

\section{Forced Rayleigh Scattering experiment}

The principle of the used Forced Rayleigh Scattering $(\text { FRS })^{3}$ setup (see Fig. 2) has been extensively described

\footnotetext{
${ }^{3}$ FRS implies forced inhomogeneities with respect to the spontaneous fluctuations observed in a classical Rayleigh scattering experiment [47].
} 


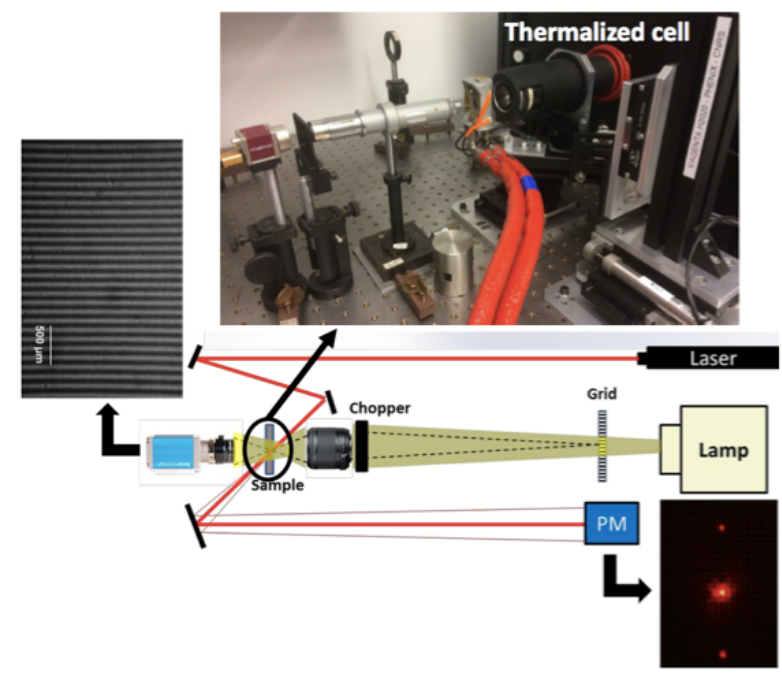

Figure 2. Experimental device - The beam of a high-power $\mathrm{Hg}$ lamp is temporally modulated thanks to a chopper. It illuminates a grid, the image of which is made in the thermoregulated (optical) sample-cell, producing a thermal and a concentration gratings in the colloidal dispersion. Both gratings are probed by the diffraction of a non-absorbed He-Ne laser beam and a photo-multiplicator (PM) records the first order diffraction as a function of time.

in Ref. [48]. Some improvements to the home-made device have been made. In particular, the modulation of the power lamp is decreased to a few $\mathrm{Hz}$ to probe more viscous systems than in Ref. [48] and the sample environment is now thermo-regulated allowing to work between $T=-40^{\circ} \mathrm{C}$ and $200^{\circ} \mathrm{C}$. However only results at $T=21 \pm 0.4^{\circ} \mathrm{C}$ are presented here.

Using a high power lamp (6285 - 500W - Hg Arc Lamp - Spectra Physics) and thanks to the strong optical absorption of the maghemite NPs, a thermal grating (of period $\Lambda$ ranging between 88 and $145 \mu \mathrm{m}$ ) is created in the dispersion, contained in an optical cell of thickness 25 or $100 \mu \mathrm{m}$. The Soret effect then induces a concentration grating in this dispersion. Both thermal and concentration gratings are here probed with the first order diffraction of a non-absorbing He-Ne laser. The Soret coefficient $S_{\mathrm{T}}$ is obtained in stationary conditions thanks to a few $\mathrm{Hz}$ modulation of the $\mathrm{Hg}$ lamp (the thermal response of the system being by orders of magnitude faster than the concentration one - see E.S.I. Sections S1 and S4). The relaxation of the concentration grating when the $\mathrm{Hg}$ lamp is off, allows to determine the mass diffusion coefficient $D_{\mathrm{m}}$ of the NPs.

With the heat source "on" (the Hg lamp heats the dispersion periodically at $8 \mathrm{~Hz}$ ) the diffracted intensity, related to both the growing concentration grating and the corresponding thermal one, is recorded as a function of time until a stationary state is reached. This diffracted intensity is converted in (i) temporal index-variations $\Delta n_{\Phi}(t)$ related to the temporal evolution of the concentration grating and (ii) temporal index-variations $\Delta n_{\mathrm{T}}$ related to the temporal evolution of the thermal grating (see E.S.I. Section S1 for more details). From the values of $\partial n / \partial T$
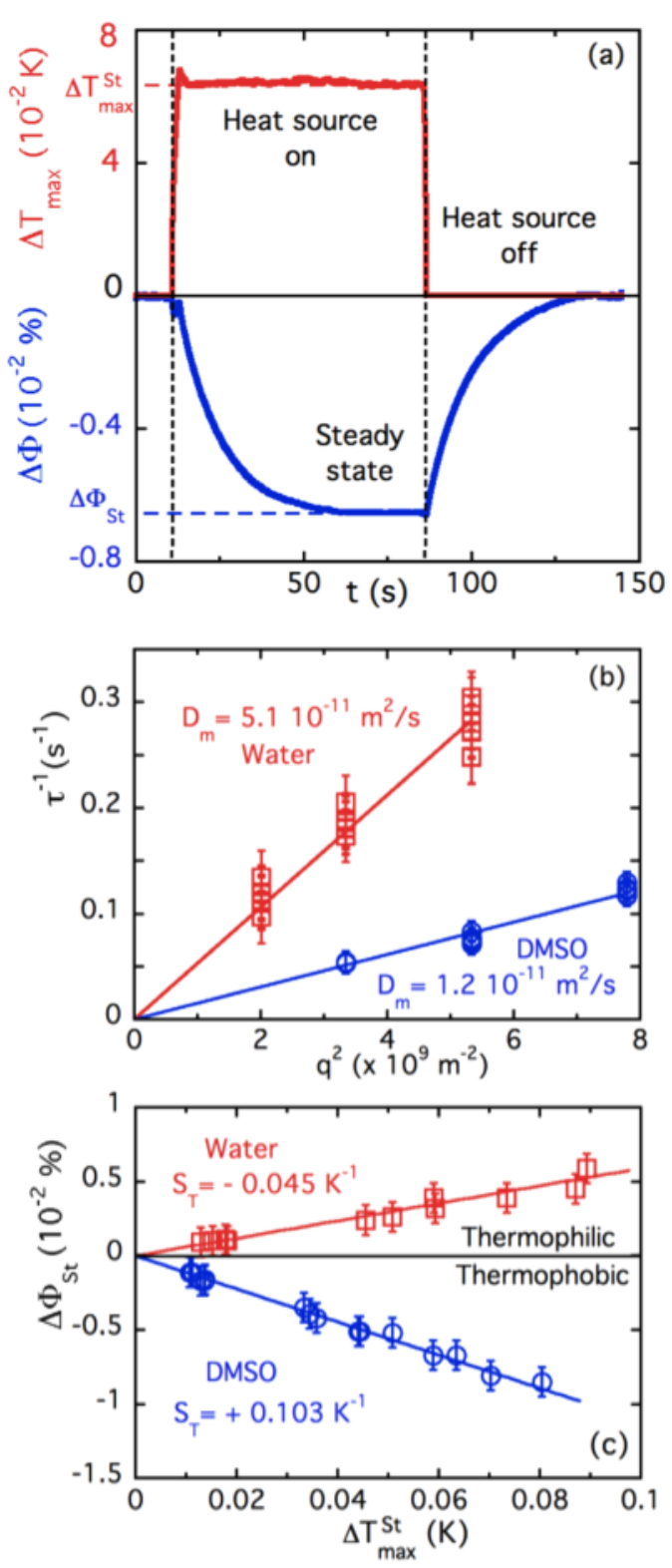

Figure 3. (a) $\Delta \Phi$ and $\Delta T_{\max }$ as a function of time for a dispersion at $\Phi=2.5 \%$ in DMSO at $q=7.14 \times 10^{4} \mathrm{~m}^{-1}$; (b) Relaxation time $\tau^{-1}$ of $\Delta \Phi$ when the heat source is off as a function of $q^{2}$ and (c) $\Delta \Phi_{s t}=f\left(\Delta T_{\max }^{S t}\right)$ for dispersions at $\Phi=2.5 \%$ in water and in DMSO at various $q$ and various powers of the lamp (in the linear regime).

and $\partial n / \partial \Phi$ (see E.S.I. Section S3), the temporal evolution $^{4}$ of $\Delta \Phi$ associated to the concentration grating and of the enveloppe $\Delta T_{\max }$ of $\Delta T$ associated to the thermal grating are determined (see Fig. 3a for a sample at $\Phi=2.5 \%$ and $q=2 \pi / \Lambda=7.14 \times 10^{4} \mathrm{~m}^{-1}(\Lambda=88 \mu \mathrm{m})$ in DMSO). When the heat source is switched off (see

\footnotetext{
${ }^{4}$ By convention (see E.S.I. Section S1) $\Delta \Phi$ is chosen here to be positive for $S_{\mathrm{T}}<0$ (particles moving towards hot regions) and to be negative for $S_{\mathrm{T}}>0$ (particles moving towards cold regions), with positive $\Delta T$ between bright and dark fringes.
} 
Fig. 3a) $\Delta T_{\max }=0$ and the diffracted intensity relaxes to zero as the concentration grating $\Delta \Phi$ relaxes exponentially to zero with a characteristic time $\tau$. Fig. 3b presents $\tau^{-1}$ as a function of $q^{2}$ in water and DMSO, at $\Phi=2.5 \%$, for different $q$ values. These two quantities are proportional to each other, showing that the relaxation is a diffusion process, the (mass) diffusion coefficient $D_{\mathrm{m}}$ being the slope of these straight lines. We obtain $D_{\mathrm{m}}=\tau^{-1} q^{-2}=5.12 \times 10^{-11} \mathrm{~m}^{2} \mathrm{~s}^{-1}$ for water and $D_{\mathrm{m}}=1.23 \times 10^{-11} \mathrm{~m}^{2} \mathrm{~s}^{-1}$ for DMSO. Different powers of the lamp (ranging between 350 and $500 \mathrm{~W}$ ) are used here to test that the response is linear and that the relaxation time $\tau^{-1}$ is independent of the power of the lamp.

Fig. 3c presents the stationary value $\Delta \Phi_{\mathrm{St}}$ of $\Delta \Phi$ as a function of $\Delta T_{\max }^{S t}$, the value of $\Delta T_{\max }$ in the steady state, for water and DMSO, at $\Phi=2.5 \%$. They are obtained for different $q$ values and different powers of the lamp (remaining in the range of linear response) to test that $\Delta \Phi_{\mathrm{St}}$ and $\Delta T_{\max }^{S t}$ remain proportional to each other, for a given sample independently of $q$ and of the lamp-power. The slope of the straight lines in Fig. 3c is proportional to the Soret coefficient $S_{\mathrm{T}}$ and as mentioned earlier they are of opposite sign in water and in DMSO. In the present experiment, the chopper, while operating, is equally open and closed. Thus the mean value of $\Delta T$ is $\langle\Delta T\rangle=\Delta T_{\max } / 2$. The Soret coefficient is then given by:

$$
S_{\mathrm{T}}=-\frac{2}{\Phi} \frac{\Delta \Phi_{\mathrm{St}}}{\Delta T_{\max }^{S t}} .
$$

Fig. 3c shows that at $\Phi=2.5 \%,\left|\Delta \Phi_{\mathrm{St}}\right|$ is always smaller than $10^{-2} \%$ while $\Delta T_{\max }^{S t} \leq 0.085 \mathrm{~K}$ for both DMSO and water. We obtain here $S_{\mathrm{T}}=-4.5 \times 10^{-2} \mathrm{~K}^{-1}$ for water and $S_{\mathrm{T}}=+0.10 \mathrm{~K}^{-1}$ for DMSO.

\section{Experimental results}

FRS measurements are performed at several molar fractions of water $x_{\mathrm{W}}$ for different NP's volume fractions $\Phi$ $(0.5 \leq \Phi \leq 2.5 \%)$ at $\left[\mathrm{H}^{+}\right]=10^{-2} \mathrm{~mol} \mathrm{~L}^{-1}$.

\subsection{Diffusion coefficient}

The mass diffusion coefficient $D_{\mathrm{m}}$ for several dispersions at different $x_{\mathrm{W}}$ is presented in Fig. 4 as a function of the volume fraction $\Phi$. For all solvent mixtures compositions, it is an increasing function of $\Phi$, as expected for the strong interparticle repulsion inside the dispersions. In the low $\Phi$ regime, where both FRS and DLS are performed Fig. 5 shows the good agreement between the two determinations of the diffusion coefficient. For all values of volume fraction, $D_{\mathrm{m}}$ is a non-monotonous function of $x_{\mathrm{W}}$, with a minimum for $x_{\mathrm{W}} \sim 0.6$, which corresponds to the maximum of the mixture viscosity given in Fig. 5. Indeed $D_{m}$ is related to the osmotic pressure $\Pi$ and the local friction $\zeta$ of the NPs in the colloidal dispersion through the following relations :

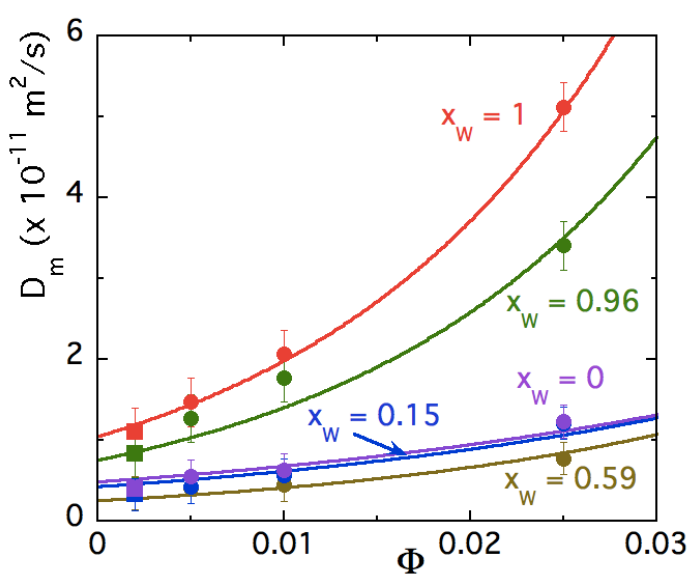

Figure 4. Diffusion coefficient $D_{\mathrm{m}}$ as a function of the NP volume fraction $\Phi$ in mixtures of water and DMSO at different $x_{\mathrm{W}}$ - from top to bottom $x_{\mathrm{W}}=1,0.96,0,0.15$ and 0.59 - as obtained from FRS measurements (circular symbols) and DLS measurements at $\Phi=0.2 \%$ (square symbols) - Full lines corresponds to Eq. 5 with $\chi(\Phi)=\chi_{\mathrm{CS}}\left(\Phi_{\text {eff }}\right)$ (see Eq. 2 ) obtained using SANS measurement of Fig. 1.

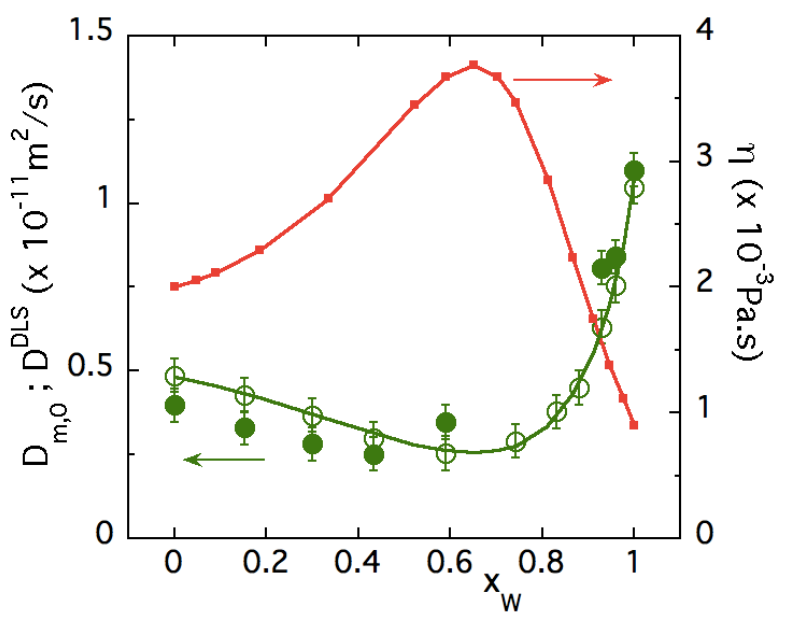

Figure 5. Viscosity $\eta$ of water-DMSO mixtures at $25^{\circ} \mathrm{C}$ as a function of the molar fraction of water $x_{\mathrm{W}}$ from Ref. [24] (small squares/ full red line); Diffusion coefficient $D_{\mathrm{m}, 0}$ obtained at $21^{\circ} \mathrm{C}$ by FRS and extrapolated at $\Phi=0$ (open circles) and $D^{\text {DLS }}$ obtained at $22^{\circ} \mathrm{C}$ and $\Phi=0.2 \%$ (full circles) as a function of $x_{\mathrm{W}}$; Full green line adjustment of $D_{\mathrm{m}, 0}=k T / \zeta_{0}$.

$$
D_{m}=\frac{1}{\zeta} \frac{\partial \Pi}{\partial n_{\mathrm{NP}}}=\frac{1}{\zeta} \frac{k T}{\chi} \quad \text { and } \quad \chi=\frac{k T}{\frac{\partial \Pi}{\partial n_{\mathrm{NP}}}}
$$

where $n_{\mathrm{NP}}=\Phi / V_{\mathrm{NP}}$ is the number of NPs per unit volume ( $V_{\mathrm{NP}}$ being the NP's volume), $\Pi$ is the osmotic pressure of the NP system and $\chi$ is its osmotic compressibility written here in the framework of Carnahan-Starling formalism of effective hard spheres used in Eqs. 2 and 3.

The full lines of Fig. 4 corresponds to the adjustment $D_{m}(\Phi)=D_{m, 0} / \chi_{\mathrm{CS}}\left(\Phi_{\text {eff }}\right)$ with $\Phi_{\text {eff }}=\Phi A_{2} / 4$ and the $A_{2}$ values presented in Fig. 1. Here it is assumed that the local 
friction $\zeta$ of the NPs in the colloidal dispersion equals $\zeta_{0}$ the friction in the solvent, neglecting any influence of the interparticle interaction on the local friction.

The initial values $D_{m, 0}$ at $\Phi=0$ and $\chi=\chi_{\mathrm{CS}}=1$ deduced from FRS experiments are presented in Fig. 5 as a function of $x_{\mathrm{W}}$, for all the probed $x_{\mathrm{W}}$. The good adjustment of $D_{m, 0}\left(x_{\mathrm{W}}\right)$ by $k T / \zeta_{0}$ (deduced from the $x_{\mathrm{W}^{-}}$ dependence of the viscosity), shows that it is the solvent viscosity which controls the variations of friction when $x_{\mathrm{W}}$ varies. This also attests the good NP's dispersion whatever the mixture as any aggregation of the NPs would lead to a significant decrease of the diffusion coefficient with respect to Eq. 5 (shown by the full line in Fig. 5). We see that the non-ideal behavior of the viscosity as a function of $x_{\mathrm{W}}$ in the water-DMSO mixtures is also observed in the experimental values of $D_{m, 0}\left(x_{\mathrm{W}}\right)$.

\subsection{Soret coefficient}

Fig. 6 presents $S_{\mathrm{T}}$ as a function of $\Phi$ for several mixtures. As previously shown in Fig. 3c the measured Soret coefficient is found positive in DMSO (at $x_{\mathrm{W}}=0$ ) and negative in water (at $x_{\mathrm{W}}=1$ ). As expected from literature $[6,16]$ the Soret coefficient is a decreasing function of the volume fraction in DMSO, while it increases with $\Phi$ in water. These behaviors are also observed in mixtures at low and large $x_{W}$ 's. In mixtures rich in water (large values of $\left.x_{W}\right) S_{\mathrm{T}}$ is negative and increases with $\Phi$ while it is positive and decreases with $\Phi$ at low $x_{\mathrm{W}}$ in mixtures rich in DMSO. At intermediate values of $x_{\mathrm{W}}$ the situation is more complicated (data not shown). The measured Soret coefficient increases with $\Phi$ and remains negative, close to the one measured at $x_{\mathrm{W}}=0.83$ down to $x_{\mathrm{W}}=0.59$. At $x_{\mathrm{W}}=0.43$ and $x_{\mathrm{W}}=0.3, S_{\mathrm{T}}$ still increases with $\Phi$ but it becomes positive at large $\Phi$ 's. Let us analyze these dependences with the following modeling.

\section{Theoretical background}

\subsection{Theoretical model}

If the dispersions of ionic NPs are submitted to small gradients of volume fraction $\nabla \Phi$ and of temperature $\nabla T$, the Ludwig-Soret coefficient $S_{\mathrm{T}}$, being defined in stationary conditions by:

$$
\nabla \Phi=-\Phi S_{\mathrm{T}} \nabla T,
$$

can be rewritten $[12,13,49,50]$ following a model ${ }^{5}$ detailed in $[6,16,17]$ as:

$$
S_{T}=\chi\left[\frac{\hat{S}_{\mathrm{NP}}}{k T}-e \xi_{0} \frac{S_{e}^{s t}}{k T}\right] .
$$

\footnotetext{
${ }^{5}$ In a first approximation, we neglect here the term $\frac{1}{n k T} \frac{\partial \Pi}{\partial T}$ which is here always smaller than $9 \times 10^{-3} \mathrm{~K}^{-1}$. As well the contribution of DMSO is not taken into account here because $\hat{S}_{\text {DMSO }} / k T$ evolves from $-2.5 \times 10^{-3} \mathrm{~K}^{-1}$ at $x_{\mathrm{W}}=0.1$ up to $+2.5 \times 10^{-3} \mathrm{~K}^{-1}$ at $x_{\mathrm{W}}=0.9$ following the results of Ref. [51]. Close to conditions where $S_{\mathrm{T}}=0$, these neglected terms could become slightly relevant.
}

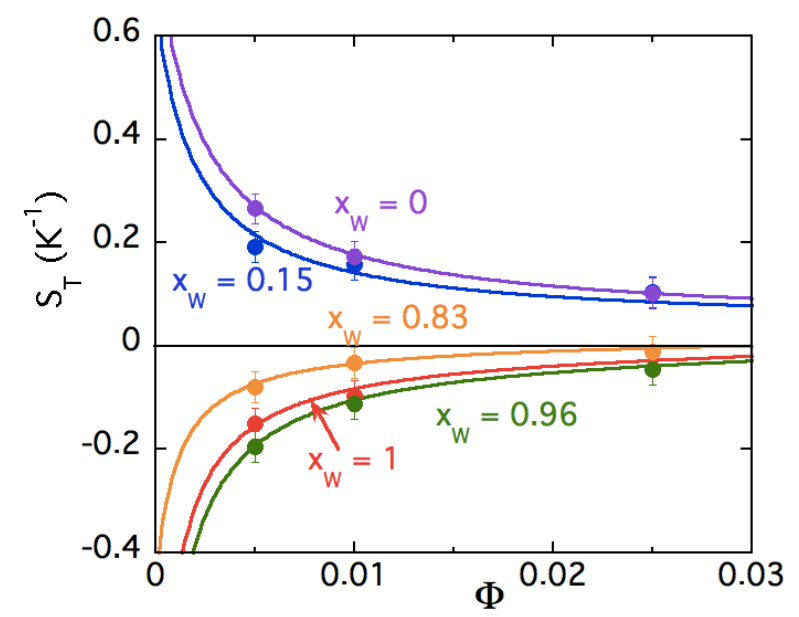

Figure 6. Soret coefficient $S_{\mathrm{T}}$ as a function of the NP volume fraction $\Phi$ in mixtures of water and DMSO for several $x_{\mathrm{W}}$ values - from top to bottom $x_{\mathrm{W}}=0 ; 0.15 ; 0.83 ; 0.96$ and 1 as obtained from FRS measurements (circular symbols). Full lines correspond to the adjustment of the results with Eqs. 7 and 8 , the entropy of transfer of ions $\left(\hat{S}_{\mathrm{H}^{+}} / k T\right.$ and $\left.\hat{S}_{\mathrm{ClO}_{4}^{-}} / k T\right)$ being deduced with the model of Section 5.2.

$\hat{S}_{\mathrm{NP}}$ is the NP Eastman entropy of transfer [11], defined as the ratio of the heat of transport of the NPs divided by $T$, which characterizes the affinity of the NPs with the solvent. The stationary Seebeck coefficient $S_{e}^{s t}$ [13] equals for monovalent free ions:

$$
e S_{e}^{s t}=\frac{n_{+} \hat{S}_{+}-n_{-} \hat{S}_{-}+Z n_{\mathrm{NP}} \chi \hat{S}_{\mathrm{NP}}}{n_{+}+n_{-}+Z n_{\mathrm{NP}} \chi \xi_{0}} .
$$

$n_{+}$(resp. $n_{-}$) are the number of free $\mathrm{H}^{+}$(resp. $\mathrm{ClO}_{4}^{-}$) ions per volume unit and $\hat{S}_{+}$(resp. $\hat{S}_{-}$) their Eastman entropy of transfer. The (static) NP's effective charge $Z$ is given by the electroneutrality of the dispersion (see Refs $[6,16,17]$ ). It is of the same order of magnitude as the (dynamic) NP's effective charges $\xi_{0}$, determined experimentally (see section 2.3). For sake of simplicity, we assimilate them to each other in the fits of $S_{\mathrm{T}}(\Phi)$.

In Eqs. 7 and 8, the only unknown quantities are the three Eastman entropies of transfer, namely $\hat{S}_{\mathrm{NP}}, \hat{S}_{+}$and $\hat{S}_{-}$. The quantities $\hat{S}_{+}$and $\hat{S}_{-}$are known in water, in the infinite dilution limit and at room temperature, from Refs. [11, 52], $\hat{S}_{\mathrm{H}^{+}} / k T=+0.018 \mathrm{~K}^{-1}$ and $\hat{S}_{\mathrm{ClO}_{4}^{-}} / k T=$ $0.000 \mathrm{~K}^{-1}$. However they are not known in water-DMSO mixtures and in pure DMSO.

\section{$5.2 \hat{S}_{\mathrm{H}^{+}}$and $\hat{S}_{\mathrm{ClO}_{4}^{-}}$evaluation in water-DMSO mixtures}

We propose here to evaluate $\hat{S}_{+}$and $\hat{S}_{-}$from the enthalpy of transfer $\Delta_{\mathrm{t}} \mathrm{H}_{\text {ion }}^{\circ}$ of $\mathrm{H}^{+}$and $\mathrm{ClO}_{4}^{-}$ions from water to water-DMSO mixtures, which are tabulated for several $x_{\mathrm{W}}$ values in Refs. $[53,54]$. Following the developments of E.S.I. Section S5, the Eastman entropy of transfer of 

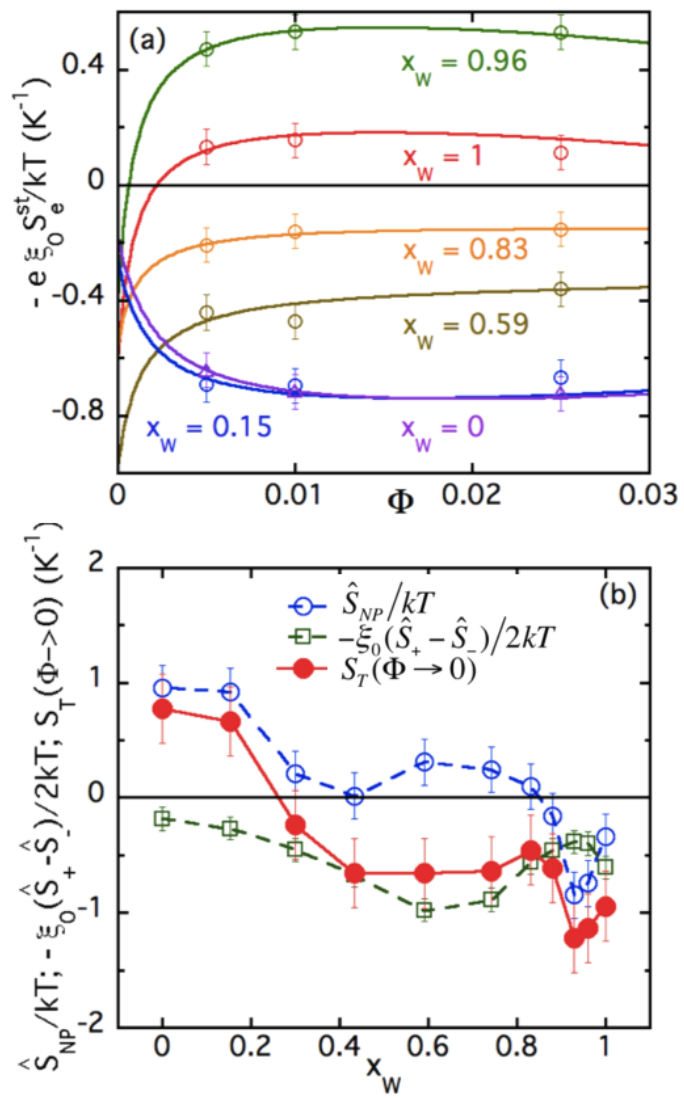

Figure 7. (a) Thermoelectric contribution $-e \xi_{0} \frac{S_{e}^{s t}}{k T}$ as a function of $\Phi$ for $x_{\mathrm{W}}=1,0.96,0.83,0.59,0.15$ and 0 as obtained with the model of Section 5.2; (b) Comparaison between $S_{\mathrm{T}}(\Phi \rightarrow 0)$ and its two contributions in Eq.11: $\frac{\hat{S}_{\mathrm{NP}}}{k T}$ (the single-particle contribution to $\left.S_{\mathrm{T}}\right)$ and $-\frac{\xi_{0}}{2}\left(\frac{\hat{S}_{+}}{k T}-\frac{\hat{S}_{-}}{k T}\right)$ (the thermoelectric contribution of ions) obtained in the framework of the model of Section 5.2 for $\hat{S}_{ \pm}$; Full line and dashed lines are guides for the eye.

the free ions $\hat{S}_{ \pm}\left(x_{\mathrm{W}}\right)$ can be expressed with the following expression:

$$
\frac{\hat{S}_{ \pm}}{k T}\left(x_{\mathrm{W}}\right)=\frac{\hat{S}_{ \pm}}{k T}\left(x_{\mathrm{W}}=1\right)-\frac{\Delta_{\mathrm{t}} H_{ \pm}^{\circ}\left(x_{\mathrm{W}}\right)}{R T^{2}},
$$

where $\Delta_{\mathrm{t}} H_{ \pm}^{\circ}\left(x_{\mathrm{W}}\right)$ is the enthalpy of transfer of $( \pm)$ ions $\left(\mathrm{H}^{+}\right.$and $\left.\mathrm{ClO}_{4}^{-}\right)$from water to the water-DMSO mixture at mole fraction of water $x_{\mathrm{W}}$. Fig. S4a of E.S.I. shows the values of $\hat{S}_{\mathrm{H}^{+}} / k T$ and $\hat{S}_{\mathrm{ClO}_{4}^{-}} / k T$ as a function of $x_{\mathrm{W}}$ as deduced from Refs $[53,54]$ and Eq. 9, together with the interpolations used here (in particular for $\mathrm{H}^{+}$for which we did not find any value of $\Delta_{\mathrm{t}} H_{\mathrm{ion}}^{\circ}\left(x_{\mathrm{W}}\right)$ for $\left.0<x_{\mathrm{W}}<0.7\right)$. Note that anyway $\hat{S}_{\mathrm{H}^{+}} / k T$ presents a non-ideal behavior, with a pronounced maximum in the vicinity of the eutectic proportion, while the variations of $\hat{S}_{\mathrm{ClO}_{4}^{-}} / k T$ as a function of $x_{\mathrm{W}}$ are smoother.

The $x_{\mathrm{W}}$-dependence of the NP's Eastman entropy of transfer $\hat{S}_{\mathrm{NP}}$ is then deduced from the measurements of $S_{\mathrm{T}}$. The results obtained from Eqs. 7, 8 and values of $\hat{S}_{\mathrm{H}^{+}} / k T$ and $\hat{S}_{\mathrm{ClO}_{4}^{-}} / k T$ are presented in Fig. $7 \mathrm{~b} . \hat{S}_{\mathrm{NP}} / k T$ decreases from $\sim+1 \mathrm{~K}^{-1}$ at $x_{\mathrm{W}}=0$ down to $\sim-0.5 \mathrm{~K}^{-1}$ at $x_{\mathrm{W}}=1$, with a "plateau" close to 0 for $0.3<x_{\mathrm{W}}<$ 0.85. In Fig. S4b of E.S.I., these results are compared to those obtained with a more basic evaluation of $\hat{S}_{ \pm}$, obtained with the Born model which only takes into account electrostatic considerations. Both methods give very comparable results (see Section S5 of E.S.I. for more details).

Using Eq. 8 and the electroneutrality relation in the solution $\left(Z n_{\mathrm{NP}}+n_{+}+n_{-}=0\right)$, the thermoelectric contribution $-e \xi_{0} S_{e}^{s t} / k T$ in Eq. 7 can be written as :

$$
-e \xi_{0} \frac{S_{e}^{s t}}{k T}=-\frac{\xi_{0}}{k T} \frac{Z \frac{n_{\mathrm{NP}}}{n_{+}}\left(\chi(\Phi) \hat{S}_{\mathrm{NP}}-\hat{S}_{-}\right)+\left(\hat{S}_{+}-\hat{S}_{-}\right)}{2+Z \frac{n_{\mathrm{NP}}}{n_{+}}\left(1+\chi(\Phi) \xi_{0}\right)}
$$

This thermoelectric contribution $-e \xi_{0} \frac{S_{e}^{s t}}{k T}$ is presented in Fig. 7a as a function of $\Phi$ for the same $x_{\mathrm{W}}$-values as in Fig. 6.

In the very dilute limit $\Phi \rightarrow 0$ and $\chi=1$, the Soret coefficient reduces to :

$$
\left.S_{\mathrm{T}}(\Phi \rightarrow 0)=\frac{\hat{S}_{\mathrm{NP}}}{k T}-\frac{\xi_{0}}{2} \quad \frac{\hat{S}_{+}}{k T}-\frac{\hat{S}_{-}}{k T}\right)
$$

the first term coming from the NPs (single particle thermophoretic contribution) and the second from the free ions (thermoelelectric contribution of free ions at $\Phi=0$ ). As an illustration of their relative importances, Fig. 7b compares these two terms to $S_{\mathrm{T}}(\Phi \rightarrow 0)$ as a function of $x_{\mathrm{W}}$. In this very dilute limit $(\Phi \rightarrow 0$ and $\chi=1)$, the single-particle contribution $\hat{S}_{\mathrm{NP}}$ from the NPs is dominant in $S_{\mathrm{T}}$ for $x_{\mathrm{W}} \leq 0.15$ (close to pure DMSO) and for $0.83 \leq x_{\mathrm{W}}<1$ (close to pure water), while on the contrary for $0.4 \leq x_{\mathrm{W}}<0.8$ it is the Seebeck contribution from the free ions, which dominates in the $S_{\mathrm{T}}$-values (both contributions are close to each other at $x_{\mathrm{W}}=1$ ). Note that close to $x_{\mathrm{W}} \sim 0.27$, where $S_{\mathrm{T}}(\Phi \rightarrow 0) \sim 0$, the contributions neglected in footnote 5 may become slightly relevant.

Moreover we observe here that the single-particle thermophoretic contribution $\hat{S}_{\mathrm{NP}}$ changes its sign around $x_{\mathrm{W}}$ $\sim 0.8$ (being negative above). This corresponds to the value of $x_{\mathrm{W}}$ where the Soret coefficient of DMSO in water changes its sign in Ref. [51] (being positive above). This "anti-correlation" could be related to the fact that whatever the solvent in which they are dispersed, these NPs always keep a layer of structural water at their surface leading to $\hat{S}_{\mathrm{NP}}$ of the same sign as the Soret coefficient of water in DMSO.

Let us note as well that, contrary to what we observe in Fig. 4 for the dynamic quantity $D_{\mathrm{m}}$, there is here no mark of non-ideality at $\Phi=0$ for the Soret coefficient $S_{\mathrm{T}}$ in the neighborhood of the eutectic proportion $x_{\mathrm{W}} \sim 0.66$, nor for any of its two components $\hat{S}_{\mathrm{NP}}$ and $S_{e}^{s t}$. This could be related to the nature of the counter-ions condensed at the NP surface, which are here $\mathrm{ClO}_{4}^{-}$and for which $\hat{S}_{-}$ 
does not present any bump at the eutectic composition (see Fig. S4a of E.S.I.).

At finite concentration, this simple description does not hold any longer since the interparticle interactions enter into play through the coefficient $\chi(\Phi)$ in Eq. 7 and the NPs contribute to the thermoelectric term $-e \xi_{0} \frac{S_{e}^{s t}}{k T}$ (see Eq. 8 and Fig. 7a).

\section{Discussion}

The Eastman entropy of transfer $\hat{S}_{\mathrm{NP}}$ of the ionic NPS is the single-particle thermophoretic contribution (all the interparticle interaction and Seebeck contributions being already eliminated). It has been shown in $[16-18]$ that $\hat{S}_{\mathrm{NP}}$ depends on all the details of the interface between the NPs and the solvent (NP's coating, nature and concentration of free counterions, nature of the solvent).

This evolution of $\hat{S}_{\mathrm{NP}}$ correlates with the evolution of the structure and the dynamics of the pure water-DMSO mixtures $[33,34]$. Indeed, adding a few DMSO molecules in water induces huge changes in the molecular organization observed in the mixtures due to strong $\mathrm{H}$ bonds interactions between DMSO and water [34]. In the range $0.85 \leq x_{\mathrm{W}} \leq 1$ where $\hat{S}_{\mathrm{NP}}$ is negative, the exchange rate of $\mathrm{H}$ bonds moreover slows down while adding DMSO due to these $\mathrm{H}$ bonds between the two solvent molecules and are for example at the origin of the cryoprotective role of DMSO for proteins in this range of $x_{\mathrm{W}}$ [33]. When increasing the DMSO content further $\left(x_{\mathrm{W}}<0.85\right)$, the dynamics of the water/surface $\mathrm{H}$ bonds should change due to the increasing number of DMSO molecules, which can also solvate the NPs surfaces [33]. As well, adding some water molecules in DMSO $\left(0 \leq x_{\mathrm{W}} \leq 0.1\right)$ modifies its organization on the molecular scale, however this does not influence much $\hat{S}_{\mathrm{NP}}$, which remains constant and positive. In the intermediate region $\left(0.1<x_{\mathrm{W}} \leq 0.65\right)$ where the structure of DMSO does not evolve much [34], $\hat{S}_{\mathrm{NP}}$ does not change much either. We recall that no special behaviour is here detected in the region of the eutectic point close to $x_{\mathrm{W}}=0.66$.

Moreover, it has been shown in Refs. [13,55-58] that two main mechanisms of ionic shielding contribute to $\hat{S}_{\mathrm{NP}}$. One is electrostatic. It is driven by the buildup of the NP's charge and of the ionic shell. It is usually described [59$61]$ with the capacitor model $\hat{S}_{\mathrm{NP}}^{\mathrm{cm}}$. The second one $\hat{S}_{\mathrm{NP}}^{\text {solv }}$ corresponds to the solvation of the NPs and of their ionic shell in the solvent [59]. $\hat{S}_{\mathrm{NP}}$ then expresses as:

$$
\hat{S}_{\mathrm{NP}}=\hat{S}_{\mathrm{NP}}^{\mathrm{cm}}+\hat{S}_{\mathrm{NP}}^{\mathrm{solv}} .
$$

The capacitor contribution can be written as :

$$
\hat{S}_{\mathrm{NP}}^{\mathrm{cm}}=\frac{\partial}{\partial T}\left[\frac{\left(e Z\left(x_{\mathrm{W}}\right)\right)^{2}}{2 \pi \varepsilon_{0} \varepsilon\left(T, x_{\mathrm{W}}\right) d_{\mathrm{NP}}\left(2+\kappa\left(T, x_{\mathrm{W}}\right) d_{\mathrm{NP}}\right)}\right]
$$

where $Z\left(x_{\mathrm{W}}\right)$ is the static effective charge in the solution (taken here equal to $\left.\xi_{0}\left(x_{\mathrm{W}}\right)\right), \varepsilon\left(T, x_{\mathrm{W}}\right)$ is the relative permittivity of the aqueous dimethyl sulfoxide solution at $x_{\mathrm{W}}$ and where $\kappa^{-1}\left(T, x_{\mathrm{W}}\right)$ is the screening length

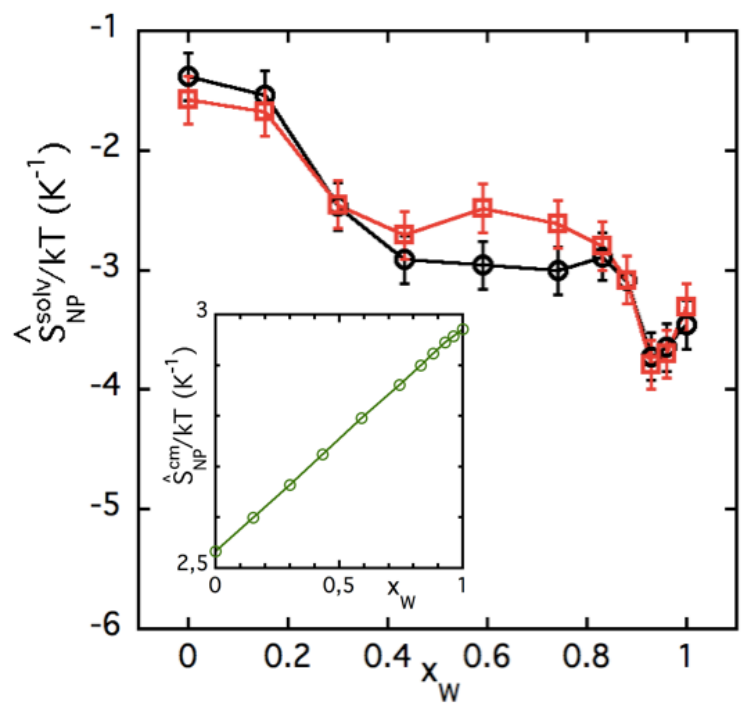

Figure 8. $\hat{S}_{N P}^{s o l v} / k T$ (main figure) and $\hat{S}_{N P}^{c m} / k T$ (inset) as a function of $x_{\mathrm{W}}$ obtained using Eqs. 12 and 13; Symbols of main figure : (Open squares) $\hat{S}_{N P}^{\text {solv }} / k T$ deduced from Fig. $7 \mathrm{~b}$ in the framework of the model of Section 5.2, (Open circles) as deduced from the Born model for $\hat{S}_{ \pm}$and Fig. S4b of E.S.I...

at $x_{\mathrm{W}} \cdot \varepsilon\left(T, x_{\mathrm{W}}\right)$ is obtained from Ref. [30]; $\xi_{0}\left(x_{\mathrm{W}}\right)$ and $d \xi_{0}\left(x_{\mathrm{W}}\right) / d T$ are deduced by linear interpolation between their measured values in water and DMSO; $\kappa^{-1}\left(x_{\mathrm{W}}\right)$ is deduced from Eq. 3 and measurements of Fig. 1.

$\hat{S}_{\mathrm{NP}}^{\mathrm{cm}}$ (see inset of Fig. 8) then varies almost linearly from $\sim+2.5 \mathrm{~K}^{-1}$ in pure DMSO to $\sim+3 \mathrm{~K}^{-1}$ in pure water; It strongly depends on $d \xi_{0} / d T$.

$\hat{S}$ sp , as obtained from Eq. 12 is presented in Fig. 8 in the framework of the model of Section 5.2 for evaluating $\hat{S}_{\mathrm{H}^{+}} / k T$ and $\hat{S}_{\mathrm{ClO}_{4}^{-}} / k T$ and compared to the values obtained with the Born model described in Section S5.1 of E.S.I.. In both cases $\hat{S}_{\mathrm{NP}}^{\text {solv }}$ is negative, as expected in water in Ref. [59] and it stays negative whatever $x_{\mathrm{W}}$, even in pure DMSO at $x_{\mathrm{W}}=0$.

It expresses a strong solvophilicity of the NPs on the

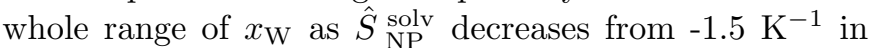
DMSO down to $\sim-3.5 \mathrm{~K}^{-1}$ at large proportion of water $\left(x_{\mathrm{W}} \geq 0.9\right)$.

\section{Summary- Perspectives}

The Soret coefficient of acidic NPs dispersed at $\left[\mathrm{H}^{+}\right]$ $=10^{-2} \mathrm{~mol} \mathrm{~L}^{-1}$ in water-dimethyl sulfoxide mixtures is measured at different mole fractions of water $x_{\mathrm{W}}$. It is observed that at low fractions of water the NPs are thermophobic $\left(S_{\mathrm{T}}>0\right)$ while at large fractions of water they are are thermophilic $\left(S_{\mathrm{T}}<0\right)$. This has to be ascribed both to the single-particle thermophoretic contribution (the socalled NP's entropy of transfer $\hat{S}_{\mathrm{NP}}$ which is linked to the particle/solvent interaction) and to the thermoelectric contribution (Seebeck term $-e \xi_{0} \frac{S_{e}^{s t}}{k T}$ in which all the charged species contribute). 
It is shown here that the single-particle thermophoretic contribution of the NPs is dominant at low and large $x_{\mathrm{W}}$ values $\left(x_{\mathrm{W}} \leq 0.15\right.$ and $\left.\geq 0.83\right)$ while it is the Seebeck term which dominates at intermediate $x_{\mathrm{W}}$. Whatever $x_{\mathrm{W}}$, the solvation contribution to $\hat{S}_{\mathrm{NP}}$ is negative, expressing a strong affinity of the ionic NPs with the mixtures of water and DMSO. However this solvation contribution is much stronger in absolute value at large water contents $x_{\mathrm{W}}$, which implies a huge role of the hydrogen-bonds of water molecules with the NPs surface in this solvation contribution. The (negative) solvation contribution then dominates the (positive) electrostatic contribution and both $\hat{S}_{\mathrm{NP}}$ and $S_{\mathrm{T}}$ are negative. On the contrary at low values of $x_{\mathrm{W}}$, the (positive) electrostatic contribution to $\hat{S}_{\mathrm{NP}}$ dominates the (negative) solvation term and gives a positive sign to $\hat{S}_{\mathrm{NP}}$, as well as to the Soret coefficient $S_{\mathrm{T}}$.

The interparticle interaction is here strongly repulsive. It imparts the systems with its colloidal stability and leads to higher NP's diffusion coefficients for larger NP's volume fractions $\Phi$, whatever $x_{\mathrm{W}}$. It is due to the strong decrease of the osmotic compressibility $\chi$ of the NP's system as $\Phi$ increases.

At low and large $x_{\mathrm{W}}$ values, whatever the $S_{\mathrm{T}}$ sign, the interparticle interaction reduces the Soret coefficient in absolute value as $\Phi$ increases, because of the decrease of $\chi$. In the intermediate range of $x_{\mathrm{W}}$, where the thermoelectric contribution becomes more important, the situation is more complicated.

Such colloidal dispersions of ionic NPs in mixtures of water and DMSO can be very useful for thermocell applications, as tuning the proportion of DMSO in the system allows to tune in sign and amplitude the Soret coefficient and the entropy of transfer of the NPs. However they can also be useful to understand the temperature evolution of hydrogen bonding in these mixtures. Indeed in the present work, only room temperature measurements have been performed and it would be also important to explore the temperature evolution of the Soret coefficient (and of the NPs entropy of transfer) at higher temperatures, and also at lower temperatures in the eutectic vicinity, for molar fraction of water $x_{\mathrm{W}} \sim 0.66$. The influence of the concentration of free ions $\left[\mathrm{H}^{+}\right]$and $\left[\mathrm{ClO}_{4}^{-}\right]$would be also important to examine, as it is a way to tune the Seebeck coefficient at finite concentration. As well it would be of paramount interest to study the influence of the nature of the counterion on the Soret coefficient. Unfortunately up to now $\mathrm{ClO}_{4}^{-}$is the only counterion that we know that leads to the colloidal stability of the dispersions of maghemite NPs in the whole range of $x_{\mathrm{W}}$ in water-DMSO mixtures.

We propose here a method to evaluate the ionic contributions $\hat{S}_{\mathrm{H}^{+}}$and $\hat{S}_{\mathrm{ClO}_{4}^{-}}$using the ionic enthalpy of transfer of $\mathrm{H}^{+}$and $\mathrm{ClO}_{4}^{-}$at room temperature. Direct experimental and/or numerical determinations of these quantities as a function of temperature, would be extremely useful in the near future to analyze the Soret coefficient in these solutions of ionic NPs as a function of $T$.

\section{Aknowledgements}

We deeply thank Amandine Anfry for the $\xi_{0}$ determinations as a function of temperature, Sawako Nakamae for useful discussions, Fabrice Cousin for his help in the SANS measurements and Laboratoire Léon Brillouin for the beamtime allocation on PACE in ORPHEE. This work has been supported by European Union's Horizon 2020 research and innovation programme under the grant $n^{\circ} 731976$ (MAGENTA).

\section{Authors contributions}

Jesse Riedl synthesized and characterized all the samples, under the supervision of Emmanuelle Dubois and Véronique Peyre. Mitradeep Sarkar realized all the FRS measurements under the supervision of Gilles Demouchy, Guillaume Mériguet and Régine Perzynski. The technical improvements of the FRS device were done by Frédéric Gélébart. The theoretical developments presented here were done in close collaboration between all the members of the team. All the authors were involved in the preparation of the manuscript. All the authors have read and approved the final manuscript.

\section{References}

1. C. Soret, Sur l'état d'équilibre que prend, au point de vue de sa concentration, une dissolution saline primitivement homogène, dont deux parties sont portées à des températures différentes, Arch. Sci. Phys. Nat. Genève 3, 48 (1879).

2. S. A. Putnam and D. G. Cahill, Transport of nanoscale latex spheres in a temperature gradient, Langmuir 21, 5317 (2005).

3. C. Goupil, W. Seifert, K. Zabrocki, E. Müller, and G. Snyder, Thermodynamics of thermoelectric phenomena and applications, Entropy 13, 1481 (2011).

4. R. Hu, B. Cola, N. Haram, J. Barisci, S. Lee, S. Stougton, G. Wallace, C. Too, M. Thomas, A. Gestos, M. dela Cruz, J. Ferraris, A. Zakhidov, and R. Baughman, Harvesting waste thermal energy using a carbon-nanotubebased thermo-electrochemical cell, Nano Letters 10, 838 (2010).

5. V. Zinovyeva, S. Nakamae, M. Bonetti, and M. Roger, Enhanced thermoelectric power in ionic liquids, ChemElectroChem 1, 426 (2014).

6. B. T. Huang, M. Roger, M. Bonetti, T. J. Salez, C. Wiertel-Gasquet, E. Dubois, R. C. Gomes, G. Demouchy, G. Mériguet, V. Peyre, M. Kouyaté, C. L. Filomeno, J. Depeyrot, F. A. Tourinho, R. Perzynski, and S. Nakamae, Thermo-electric diffusion of magnetic nanoparticles: alternative path toward future thermocell applications, J. Chem. Phys. 143, 0549021 (2015).

7. T. J. Salez, B. T. Huang, M. Rietjens, M. Bonetti, C. Wiertel-Gasquet, M. Roger, C. L. Filomeno, E. Dubois, R. Perzynski, and S. Nakamae, Can charged colloidal particles increase the thermoelectric energy conversion efficiency?, Phys. Chem. Chem. Phys. 19, 9409 (2017). 
8. M. Dupont, D. MacFarlane, and J. Pringle, Thermoelectrochemical cells for waste heat harvesting - progress and perspectives, Chem. Commun. 53, 6288 (2017).

9. D. Al-Masri, M. Dupont, R. Yunis, D. R. MacFarlane, and J. M. Pringle, The electrochemistry and performance of cobalt-based redox couples for thermoelectrochemical cells., Electrochim. Acta 269, 714 (2018).

10. T. J. Salez, S. Nakamae, R. Perzynski, G. Mériguet, A. Cēbers, and M. Roger, Thermoelectricity and thermodiffusion in magnetic nanofluids: Entropic analysis, Entropy 20, 4051 (2018).

11. J. N. Agar, C. Y. Mou, and J. L. Lin, Single ion heat of transport in electrolyte solutions, J. Phys. Chem. 93, 2079 (1989).

12. A. Würger, Transport in Charged Colloids Driven by Thermoelectricity, Phys. Rev. Lett. 101, 108302 (2008).

13. A. Majee and A. Würger, Collective thermoelectrophoresis of charged colloids, Phys. Rev. E 83, 061403 pp. 1 (2011).

14. A. Majee, Effet thermoélectrique dans les dispersions colloïdale, Ph.D. thesis, Université Bordeaux I (2012).

15. M. Reichl, M. Herzog, A. Gotz, and D. Braun, Why charged molecules move across a temperature gradient : the role of electric fields, Phys. Rev. Lett. 112, 198101 pp.1 (2014).

16. R. Cabreira-Gomes, A. F. da Silva, M. Kouyaté, G. Demouchy, G. Mériguet, R. Aquino, E. Dubois, S. Nakamae, M. Roger, J. Depeyrot, and R. Perzynski, Thermodiffusion of repulsive charged nanoparticles - the interplay between single-particle and thermoelectric contributions, Phys. Chem. Chem. Phys. 20, 16402 (2018).

17. M. Kouyaté, C. Filomeno, G. Demouchy, G. Mériguet, S. Nakamae, V. Peyre, M. Roger, A. Cebers, J. Depeyrot, E. Dubois, and R. Perzynski, Thermodiffusion of citratecoated $\gamma-\mathrm{Fe}_{2} \mathrm{O}_{3}$ nanoparticles in aqueous dispersions with tuned counter-ions - anisotropy of the soret coefficient under magnetic field, Phys. Chem. Chem. Phys. 4, 1895 (2019).

18. C. L. Filomeno, M. Kouyaté, F. Cousin, G. Demouchy, E. Dubois, L. Michot, G. Mériguet, R. Perzynski, V. Peyre, J. Sirieix-Plénet, and F. A. Tourinho, Ionic magnetic fluids in polar solvents with tuned counter-ions, J. Magn. Magn. Mat. 431, 2 (2017).

19. C. L. Filomeno, M. Kouyaté, V. Peyre, G. Demouchy, A. F. C. Campos, R. Perzynski, F. A. Tourinho, and E. Dubois, Tuning the solid/liquid interface in ionic colloidal dispersions: Influence on their structure and thermodiffusive properties, J. Phys. Chem. C 121, 5539 (2017).

20. Y. Marcus, Effect of ions on the structure of water: Structure making and breaking, Chem. Rev. 109, 1346 (2009).

21. I. Plowas, J. Swiergiel, and J. Jadzyn, Electrical conductivity in dimethyl sulfoxide plus potassium iodide solutions at different concentrations and temperatures., J. Chem. Eng. Data 59, 2360 (2014).

22. J. Kiefer, K. Noack, and B. Kirchner, Hydrogen bonding in mixtures of dimethyl sulfoxide and cosolvents, Curr. Phys. Chem. 1, 340 (2011).

23. D. Rasmussen and A. M. Kenzie, Phase diagram for the system water-dimethylsulphoxide, Nature 220, 1315 (1968).

24. J. Cowie and P. Toporowski, Association in the binary liquid system dimethyl sulphoxide - water, Can. J. Chem. 39, 2240 (1961).
25. R. LeBel and D. Goring, Density, viscosity, refractive index, and hygroscopicity of mixtures of water and dimethyl sulfoxide, J. Chem. Eng. Data 7, 100 (1962).

26. C. Nieto-Draghi, J. B. Avalos, and B. Rousseau, Transport properties of dimethyl sulfoxide aqueous solutions, J. Chem. Phys. 119, 4782 (2003).

27. H. Zhang, G. Zhao, H. Ye, X. Ge, and S. Cheng, An improved hot probe for measuring thermal conductivity of liquids., Meas. Sci. Technol. 16, 1430 (2005).

28. J.-C. Zhou, Y.-Y. Che, K.-J. Wu, J. Shen, and C.H.He, Thermal conductivity of DMSO $+\mathrm{C}_{2} \mathrm{H}_{5} \mathrm{OH}$, DMSO + $\mathrm{H}_{2} \mathrm{O}$, and DMSO $+\mathrm{C}_{2} \mathrm{H}_{5} \mathrm{OH}+\mathrm{H}_{2} \mathrm{O}$ mixtures at $T=$ (278.15 to 338.15 K), J. Chem. Eng. Data 58, 663 (2013).

29. U. Kaatze, R. Pottel, and M. Schafer, Dielectric spectrum of dimethyl sulfoxide/water mixtures as a function of composition, J. Phys. Chem. 93, 5623 (1989).

30. A. Luzar, Dielectric behaviour of DMSO-water mixtures. an hydrogen-bonding model, J. Mol. Liq. 46, 221 (1990).

31. Y. Doucet, F. Calmes-Perrault, and M.-T. Durand, La constante diélectrique du diméthylsulfoxyde pur et de ses mélanges aqueux, C. R. Acad. Sci. Paris 260, 1878 (1965).

32. M. Skaf, Molecular dynamics study of dielectric properties of water-dimethyl sulfoxide mixtures, J. Phys. Chem. A 103, 10719 (1999).

33. S. M. Kashid, G. Y. Jin, S. Chakrabarty, Y. S.Kim, and S. Bagchi, Two-dimensional infrared spectroscopy reveals cosolvent-composition dependent crossover in intermolecular hydrogen-bond dynamics, J. Phys. Chem. Lett. 8, 1604 (2017).

34. K. Oh, K. Rajesh, J. Stanton, and C. Baiz, Quantifying hydrogen-bond populations in dimethyl sulfoxide/water mixtures, Ange. Chem. Int. Ed. 56, 11375 (2017).

35. A. K. Soper and A. Luzar, A neutron-diffraction study of dimethyl-sulfoxide water mixtures, J. Chem. Phys. 97, 1320 (1992).

36. A. Perera and R. Mazighi, On the nature of the molecular ordering of water in aqueous DMSO mixtures, J. Chem. Phys. 143, 154502 (2015).

37. S. Banerjee, S. Roy, and B. Bagchi, Enhanced pair hydrophobicity in the water-dimethyl sulfoxide (DMSO) binary mixture at low DMSO concentrations, J. Phys. Chem. B 114, 12875 (2010).

38. S. Roy and B. Bagchi, Solvation dynamics of tryptophan in water-dimethyl sulfoxide binary mixture: In search of molecular origin of composition dependent multiple anomalies., J. Chem. Phys. 139, 034308 (2013).

39. R. Massart, Préparation de ferrofluides aqueux en l'absence de surfactant; comportement en fonction du $\mathrm{pH}$ et de la nature des ions présents en solution, C. R. Acad. Sci. Paris, Série C 291, 1 (1980).

40. R. Massart, Preparation of aqueous magnetic liquids in alkaline and acidic media, I.E.E.E. Trans. Mag. Magn. 17, 1247 (1981)

41. J. A. Gomes, M. H. Sousa, F. A. Tourinho, R. Aquino, G. J. da Silva, J. Depeyrot, E. Dubois, and R. Perzynski, Synthesis of core-shell ferrite nanoparticles for ferrofluids : chemical and magnetic analysis, J. Phys. Chem. C 112, 6220 (2008).

42. R. Massart, E. Dubois, V. Cabuil, and E. Hasmonay, Preparation and properties of monodisperse magnetic fluids, J. Magn. Magn. Mat.M 149, 1 (1995).

43. B. Berkovski, ed., Magnetic Fluids and Applications Handbook (Begell House Inc. Publ., New York 1996). 
44. E. Wandersman, A. Cēbers, E. Dubois, G. Mériguet, A. Robert, and R. Perzynski, The cage elasticity and under-field structure of concentrated magnetic colloids probed by small-angle X-ray scattering, Soft Matter 9, 11480 (2013).

45. N. F. Carnahan and K. E. Starling, Thermodynamic properties of a rigid-sphere fluid, J. Chem. Physics 53, 600 (1970).

46. J. A. Barker and D. Henderson, Perturbation theory and equation of state for fluids. II. a successful theory of liquids, J. Chem. Phys. 47, 4714 (1967).

47. Y. Nagasaka, T. Hatakeyama, M. Osuka, and A. Nagashima, Measurement of the thermal diffusivity of liquids by the forced Rayleigh scattering method: Theory and experiment, Rev. Sci. Instrum. 59, 1156 (1988).

48. G. Demouchy, A. Mezulis, A. Bée, D. Talbot, J.-C. Bacri, and A. Bourdon, Diffusion and thermodiffusion studies in ferrofluids with a new two-dimensional forced Rayleighscattering technique, J. Phys. D: Appl. Phys. 37, 1417 (2004).

49. R. Piazza and A. Parola, Thermophoresis in colloidal suspensions, J. Phys.: Condens. Matter 20, 153102 pp. 1 (2008).

50. J. Burelbach, D. Frenkel, I. Pagonabarraga, and E. Eiser, A unified description of colloidal thermophoresis, Eur. Phys. J. E 41, 7 p.1 (2017).

51. H. Ning and S. Wiegand, Experimental investigation of the soret effect in acetone/water and dimethylsulfoxide/water mixtures, J. Chem. Phys. 125, 221102 p.1 (2006).

52. N. Takeyama and K. Nakashima, Proportionality of intrinsic heat of transport to standard entropy of hydration for aqueous ions, J. Solution Chem. 17, 305 (1988).

53. G. Hefter, Y. Marcus, and W. Waghome, Enthalpies and entropies of transfer of electrolytes and ions from water to mixed aqueous organic solvents, Chem. Rev. 102, 2773 (2002).

54. Y. Marcus, Ion properties (Marcel Dekker, New York 1997).

55. J. K. G. Dhont and W. J. Briels, Single-particle thermal diffusion of charged colloids: double-layer theory in a temperature gradient., Eur. Phys. J. E 25, 61 (2008).

56. D. Vigolo, S. Buzzaccaro, and R. Piazza, Thermophoresis and thermoelectricity in surfactant solutions., Langmuir 26, 7792 (2010).

57. M. Yang and M. Ripoll, Thermophoretically induced flow field around a colloidal particle, Soft Matter 9, 4661 (2013).

58. K. A. Eslahian, A. Majee, M. Maskos, and A. Würger, Specific salt effects on thermophoresis of charged colloids, Soft Matter 10, 1931 (2014).

59. S. Duhr and D. Braun, Why molecules move along a temperature gradient., Proc. Natl. Acad. Sci. U.S.A. 103, 19678 (2006).

60. J. K. G. Dhont, S. Wiegand, S. Duhr, and D. Braun, Thermodiffusion of charged colloids: single-particle diffusion., Langmuir 23, 1674 (2007).

61. H. Ning, J. K. G. Dhont, and S. Wiegand, Thermaldiffusive behavior of a dilute solution of charged colloids., Langmuir 24, 2426 (2008). 